\section{Expressions of TLR4, MyD88, IRAK4 and NF-KB in the oviduct of Chinese brown frog (Rana dybowskii)}

\author{
Yue Zhang, Ao Zhang, Yue Zhao, \\ Xiaohang Feng, Yuyao Sheng, Haolin \\ Zhang, Qiang Weng, Meiyu Xu \\ College of Biological Science and \\ Technology, Beijing Forestry University, \\ Beijing, China
}

\begin{abstract}
One special physiological phenomenon of the Chinese brown frog (Rana dybowskii) is that its oviduct goes through expansion prior to pre-hibernation instead of expanding during the breeding period. Our previous study discovered that some cytokines such as interleukin-1 beta (IL-1 $\beta$ ) and its receptor type I (IL1R1) proteins were expressed in the oviduct of Rana dybowskii. In this study, we continued to investigate the localizations and expression levels of cytokines including toll-like receptor 4 (TLR4) and its related factors, myeloid differentiation factor 88 (MyD88), interleukin-1 receptor-associated kinase (IRAK) and nuclear factor kappa B (NF- $\kappa \mathrm{B})$ in the oviduct of Rana dybowskii during the breeding period and pre-hibernation. Morphological results showed that there were significant differences in oviductal weight and pipe diameter with significantly higher values in pre-hibernation than those of the breeding period. Strong immunostaining of TLR4, MyD88, IRAK4 and NF$\kappa \mathrm{B}$ were observed in the pre-hibernation. These proteins levels had no significant difference between these two periods except MyD88 which was significantly higher in the pre-hibernation. The mRNA expression levels of MyD88 and NF-kB were obviously higher in pre-hibernation than those of the breeding period. These findings suggested that TLR4/MyD88 signal pathway might participate in the oviductal functions of Rana dybowskii during the breeding period and pre-hibernation.
\end{abstract}

\section{Introduction}

The female genital tract shows changes in structure and functional development to fit seasonal reproductive activities. During the estrous cycle, the oviduct is extremely sensitive to the fluctuation of $17 \beta$-estradiol and progesterone. As a result, its morphology and function change periodically to best support the reproductive processes. ${ }^{1,2}$ The oviduct is not only a passive channel for gamete and embryo transport, but also a highly active secretory organ and its oviductal fluid formed by the oviduct epithelium and plasma plays an important role in the reproductive process. For example, it can provide the optimal microenvironment for the final gamete maturation, sperm capacitation, fertilization, and the early embryonic development. Furthermore it can also provide a fine-tuned immune system to get over potential pathogens. ${ }^{3-5}$ In female genital tract, there are a large number of microorganisms that may cause disease such as inflammation of the oviduct and its immune system has the ability of dealing with pathogenic microorganism. ${ }^{6}$ For example, some report has shown that TLR4 is expressed in different types of uterine and oviductal cells of rabbit and their levels are increased by lipopolysaccharide (LPS) administration suggesting that their involvement in innate immunity for host defense was also found in the rabbit. ${ }^{?}$

Through pattern recognition receptors (PRRs) expressed on host cells, the innate immune system can recognizes pathogenassociated molecular patterns (PAMPs) and induces immune responses, thereby rendering invading pathogenic microorganisms resistant. ${ }^{8}$ Toll-like receptors (TLRs) are the major receptors for the innate immune system to recognize PAMPs that activate downstream signaling pathways to regulate immune responses. ${ }^{9}$ After recognition of PAMP, TLRs initiates a signal transduction cascade through two major pathways: i) MyD88-dependent transduction pathway; ii) MyD88-independent transduction pathway. Both of these pathways can induce the expression of a large number of related immune genes by activating various transcription factors. ${ }^{10-12}$ After recognition of PAMP, TLRs first recruit MyD88 which activates the IRAK in MyD88-mediated TLR signaling. ${ }^{8}$ Afterwards, I-kappa B kinase (IKK) complex was activated by IRAK, then phosphorylated, degraded and dissociated from NF- $\kappa \mathrm{B}$, resulting in activation of NF- $\kappa$ B. This induces downstream signaling cascades and eventually leads to the expression of genes encoding inflammatory factors such as IL-1 $\beta$, IL-6 and TNF$\alpha .^{13-15}$

Rana dybowskii is a special amphibian mainly distributed in the wooded regions of Korea, Japan and the northeast of China. ${ }^{16,17}$ The hibernation period of Rana dybowskii ranges from October to February of the following year, and then the breeding period ranges from February to June dependent on the latitude. ${ }^{4}$ One special physiological phenomenon of Rana dybowskii is that its oviducts goes through expansion prior to
Correspondence: Meiyu Xu, College of Biological Sciences and Biotechnology, Beijing Forestry University, Beijing 100083, China. Fax: +86.10.62336700. E-mail: xumeiyu@bjfu.edu.cn

Key words: Rana dybowskii; oviduct; MyD88; TLR4; IRAK4; NF-кB.

Conflict of interest: the authors declare no competing interests.

Acknowledgments: This research work is supported by Beijing Natural Science Foundation (8182039) and National Natural Science Foundation of China $(31872320,21806010)$ and Young Scientist Start-up funding of Beijing Forestry University (BLX201714).

Contributions: YZ, AZ, YZ, experiments performing, data analysis, manuscript drafting; $\mathrm{XF}, \mathrm{SS}$, samples collection assistance, experiments performing; HZ, QW, MX study design and supervision, manuscript revision. All authors read and approved the final version.

Received for publication: 11 June 2019.

Accepted for publication: 4 September 2019.

This work is licensed under a Creative Commons Attribution-NonCommercial 4.0 International License (CC BY-NC 4.0).

(C) Copyright: the Author(s), 2019

Licensee PAGEPress, Italy

European Journal of Histochemistry 2019; 63:3050 doi:10.4081/ejh.2019.3050

hibernation instead of expanding during the breeding period. The dry product of expanded oviduct called rana oil has been widely used in traditional Chinese medicine. ${ }^{17}$ Previous study has shown that IL-1 $\beta$ and IL1R1 proteins have significant higher expressions in the oviduct of Rana dybowskii during pre-hibernation than those of the breeding period. ${ }^{18}$ To extend our understanding of the regulation of oviductal functions in Rana dybowskii, we investigated localization and expression levels of TLR4/MyD88 signal pathway in Rana dybowskii oviducts during the breeding period and pre-hibernation, aiming to clarify the relationship between the TLR4/MyD88 signaling pathway and the oviductal functions in Rana dybowskii.

\section{Materials and Methods}

\section{Animals}

Adult female Rana dybowskii were obtained in April (the breeding period, $\mathrm{n}=$ 25), and October (pre-hibernation, $\mathrm{n}=25$ ) from Jilin Baekdu Moutain Chinese Brown 
Frog Breeding Farm, Jilin province, China. All experimental animals were treated in accordance with Animal Ethic Committee at the Experimental Center of Beijing Forestry University and all experimental procedures were carried out following its guidelines. Both the left and right oviducts were obtained from Rana dybowskii after the treatment of diethyl. The left side of oviduct was fixed for $24 \mathrm{~h}$ in $4 \%$ paraformaldehyde in $0.05 \mathrm{M}$ PBS, pH 7.4 for histological and immunohistochemical analysis. The right side of oviduct was stored at $-80^{\circ} \mathrm{C}$ for protein and RNA extraction.

\section{Histology}

Before embedding, the oviduct samples were dehydrated with a certain concentration of ethanol $(70 \%$ for $2 \mathrm{~h}, 80 \%$ for $2 \mathrm{~h}$, $90 \%$ for $2 \mathrm{~h}, 95 \%$ for $1.5 \mathrm{~h}, 100 \%$ for 30 min for twice) and xylene ( 3 min each, three times) and immersed in paraffin $(1 \mathrm{~h}$ each, three times) before embedding. Serial sections $(4-6 \mu \mathrm{m})$ were mounted on slides coated with poly-L-lysine (Sigma, St. Louis, MO, USA) and baked in a drying oven at $37^{\circ} \mathrm{C}$ for several hours. Sections were stained with hematoxylin and eosin (HE) to observe general histology.

\section{Immunohistochemistry}

Serial sections of the oviduct samples were deparaffinized with xylene (5 min each, three times) and a serial concentration of ethanol (100\% $5 \mathrm{~min}$ for twice, $95 \%$ for $5 \mathrm{~min}, 90 \%$ for $5 \mathrm{~min}, 80 \%$ for $5 \mathrm{~min}, 70 \%$ for $5 \mathrm{~min}$ ) and then heated in a heat-induced epitope repair buffer $(10 \mathrm{mM} \mathrm{pH} 6.0$ citric acid buffer) and allowed to cool naturally. Endogenous peroxidase blocking was performed using 3\% hydrogen peroxide buffer dissolved in $100 \%$ methanol at room temperature for $30 \mathrm{~min}$ before incubating the sections with $10 \%$ normal goat serum to reduce background staining by the secondary antibody. The serial sections were then incubated with antibody against TLR4 (bs20595R, Beijing Biosynthesis Biotechnology Co., Beijing, China), MyD88(bs-1047R, Beijing Biosynthesis Biotechnology Co.), IRAK4 (bs-2440R, Beijing Biosynthesis Biotechnology Co.) and NF- $\kappa$ B p65 subunit (bs-3485R, Beijing Biosynthesis Biotechnology Co.), with a 1:500 dilution for $12 \mathrm{~h}$ at $4^{\circ} \mathrm{C}$ The control sections were treated with normal rabbit serum (Sigma). The sections were then incubated with a second antibody for 30 min at room temperature, goat anti-rabbit conjugated with biotin and then peroxidase with avidin. The sections were visualized using 3,3'-diaminobenzidine (DAB) buffer, which contains $150 \mathrm{~mL}$ of $0.05 \mathrm{M}$ Tris- $\mathrm{HCl}$ buffer, $\mathrm{pH} 7.6,30 \mathrm{mg}$ of DAB (Wako,
Tokyo, Japan) plus $30 \mu \mathrm{L} \mathrm{H}_{2} \mathrm{O}_{2}$. Finally, the reacted sections for TLR4, MyD88, IRAK4 and NF- $\mathrm{NB}$ p 65 subunit were counterstained with hematoxylin solution (Merck, Tokyo, Japan). The immunohistochemical staining was determined as positive $(+)$, strong positive $(++)$, very strong positive $(+++)$, and negative (-). Staining that was weak but higher than control was set as positive $(+)$; the highest intensity staining was set as very strong positive $(+++)$; staining intensity between $(+)$ and $(+++)$ was set as strong positive $(++)$.

\section{Western blotting}

Briefly, $0.1 \mathrm{~g}$ of oviduct tissue were weighted exactly, then homogenized with 1 $\mathrm{mL}$ of RIPA lysate containing $1 \%$ phenylmethanesulfonyl fluoride (PMSF) in a homogenizer for $30 \mathrm{~min}$ on ice. The homogenate was centrifuged at $12,000 \mathrm{~g}$ for $10 \mathrm{~min}$ at $4^{\circ} \mathrm{C}$. Equal volume of $2 \times$ Laemmli sample buffer was mixed with the protein extracts. Each sample was loaded with an equal amount and ran on a $12 \%$ SDS-PAGE gel at $18 \mathrm{~V} / \mathrm{cm}$ and then transferred to nitrocellulose membranes using a wet transblotting apparatus (Bio-Rad Laboratories, Shanghai, China) for $1 \mathrm{~h}$. The membranes were blocked in 3\% BSA for 1 $\mathrm{h}$ at room temperature. Primary incubation of the membranes was performed for $1 \mathrm{~h}$ using a rabbit anti-rat TLR4, MyD88, IRAK4, and NF- $\kappa$ Bp65 subunit diluted into $1: 800$. Second incubation of the membranes was then performed for $1 \mathrm{~h}$ using a 1:1000 dilution of goat anti-rabbit IgG (bs-0295G, Beijing Biosynthesis Biotechnology Co., China) tagged with horseradish peroxidase. Finally, the membrane was colored with 10 mg DAB (Wako) solution in $50 \mathrm{~mL}$ phosphate buffer $(0.03 \mathrm{M})$ plus $3 \mu \mathrm{L} \mathrm{H}_{2} \mathrm{O}_{2}$. $\beta$ actin (AM1829B, Abgent Co., San Diego, CA, USA) was used as an endogenous control. Quantity One software (ver. 4.5, BioRad Laboratories) was used to quantify the bands intensity.

\section{RNA isolation}

Total RNA from oviduct tissue sample was extracted using TRIzol Reagent (Invitrogen, Carlsbad, CA, USA). $0.1 \mathrm{~g}$ of oviduct tissue were weighted exactly and ground in liquid nitrogen and homogenized in $1 \mathrm{~mL}$ of TRIzol Reagent immediately. The homogenate was allowed to stand at room temperature for $5 \mathrm{~min}$ to completely separate the nucleoprotein complex. Before centrifuging at $12,000 \mathrm{~g}$ for $15 \mathrm{~min}$ at $4{ }^{\circ} \mathrm{C}$, $0.2 \mathrm{~mL}$ chloroform was added and the mixture was vigorously shaken for $15 \mathrm{~s}$ at room temperature. After transferring the supernatant into a new fresh tube, 0.8 times volume of isopropanol (Beijing Hondar collet Technology Co., Beijing, China) was added. Next, samples were kept at room temperature for $10 \mathrm{~min}$ and precipitate RNA by centrifugation at $13,000 \mathrm{~g}$ for 10 min at $4^{\circ} \mathrm{C}$. Washing the RNA precipitation with $70 \%$ ethanol for twice, allow it to air dry naturally. Adding $60 \mu \mathrm{L}$ of diethylprocarbonate-treated water (Beijing Hondar collet Technology Co.,) dissolve the RNA.

\section{Real-time PCR quantification}

Through StarScript II First-strand cDNA Synthesis Mix (GenStar, Beijing, China), the first-strand cDNA from total RNA was synthesized. The $10 \mu \mathrm{L}$ of reaction mixture contained $1.5 \mu \mathrm{L}$ of total RNA, $0.5 \mu \mathrm{L}$ of Random Primer, $0.5 \mu \mathrm{L}$ of StarScript II RT Mix, $5 \mu \mathrm{L}$ of $2 \times$ Reaction mix, $2.5 \mu \mathrm{L}$ of diethylprocarbonate- $\mathrm{ddH}_{2} \mathrm{O}$ according to the manufacturer's protocol. The cDNA was stored at $-20^{\circ} \mathrm{C}$. Primers used are listed in Table 1. The mRNA expressions of TLR4, MyD88, IRAK4 and $\mathrm{NF}-\kappa \mathrm{B}$ during the breeding period and prehibernation were analyzed by real-time PCR using one-step SYBR PrimeScript RTPCR kit (TaKaRa Company, Dalian, China). The PCR reactions were carried out in a $20 \mu \mathrm{L}$ volume and performed with $\mathrm{ABI}$ PRISM 7500 Fast Real-Time PCR System (Applied Biosystems, Foster City, CA, USA) using the following conditions:

Table 1. Oligonucleotide primers used for quantitative Real-Time PCR.

\begin{tabular}{|c|c|c|}
\hline & Sequence of primer & Product size (bp) \\
\hline TLR4 & $\begin{array}{l}\text { CGTCAGATGTACTCCACC (forward) } \\
\text { GAAACTCAATGAGATCTGC (reverse) }\end{array}$ & 133 \\
\hline MyD88 & $\begin{array}{l}\text { CGCCACCGTTACAAGTTGAA (forward) } \\
\text { AATGCATCAAACAGCTCGGG (reverse) }\end{array}$ & 100 \\
\hline IRAK4 & $\begin{array}{l}\text { GCTGCTTCTCTTCTGCTTCC (forward) } \\
\text { GCTGCTGACATCTCACATGG (reverse) }\end{array}$ & 194 \\
\hline$N F-\kappa B$ & $\begin{array}{l}\text { GAAAAGTCACAGCCAAGCCA (forward) } \\
\text { CGCTGTCACACAAACTGTCA (reverse) }\end{array}$ & 136 \\
\hline$A c t b$ & $\begin{array}{l}\text { AACCCTCTTAGAAACCGGCA (forward) } \\
\text { AAGCGTAAAGTGCCAGGTTG (reverse) }\end{array}$ & 103 \\
\hline
\end{tabular}


reverse transcription at $42^{\circ} \mathrm{C}$ for $5 \mathrm{~min}$ and $95^{\circ} \mathrm{C}$ for $30 \mathrm{~s}$, followed by PCR reaction of 40 cycles at $95^{\circ} \mathrm{C}$ for $5 \mathrm{~s}$ and $60^{\circ} \mathrm{C}$ for $34 \mathrm{~s}$ and dissociation protocol. Transcript levels of the target genes were normalized to the Actb after correcting for differences in amplification efficiency. The expression level of each target mRNA relative to Actb mRNA was determined using the $2^{-\Delta \Delta \mathrm{Ct}}$ method.

\section{Statistical analysis}

Statistical comparisons of Student's ttest and correlation analysis were performed using GraphPad Prism 6. Values of $\mathrm{P}<0.05$ were considered to be indicative of statistical significance.

\section{Results}

\section{Morphology}

Morphological observations of Rana dybowskii oviducts during the breeding period and pre-hibernation were shown in Figure $1 \mathrm{a}, \mathrm{b}$. The oviductal weight was significantly higher in pre-hibernation $(3.30 \pm 0.28 \mathrm{~g})$ than the breeding period $(0.24 \pm 0.06 \mathrm{~g})$ (Figure 1c). Furthermore, the relative pipe diameter value also showed a significant difference in oviductal weight with values markedly higher in pre-hibernation $(0.23 \pm 0.02 \mathrm{~cm})$ than the breeding period $(0.71 \pm 0.03 \mathrm{~cm})$ (Figure 1d).

\section{Histology}

The histological observations of Rana dybowskii oviducts during the breeding period and pre-hibernation were shown in Figure 2. The oviduct of Rana dybowskii was consisted of epithelial cells, glandular cells and tubule lumen (Figure $2 \mathrm{a}, \mathrm{b}$ ). The epithelial cells were divided into epithelial cells without cilia in the pre-hibernation and epithelial cells with cilia in the breeding period, which was in accordance with previous studies. ${ }^{18}$ Cilia were observed predominantly in the epithelial cells during the breeding period, but not in the pre-hibernation (Figure $2 \mathrm{c}, \mathrm{e}$ ). Glandular cells were obviously expanded in the pre-hibernation compared to the breeding period, while the epithelial cells were not observed enlargement (Figure $2 \mathrm{~d}, \mathrm{f}$ ). The lumens of gland in the pre-hibernation were also not as evident as those in the breeding period (Figure 2 $d, f)$.

\section{Immunolocalizations for TLR4, MyD88, IRAK4 and NF-אB in Rana dybowskii oviducts}

Immunoreactivities of TLR4, MyD88, IRAK4 and NF- $\kappa \mathrm{B}$ were detected in the oviducts of Rana dybowskii during the breeding period and pre-hibernation (Figure $3)$. Comparison of positive staining intensity between the two periods was summarized in Table 2. Positive staining of TLR4 was observed in the epithelial cells with cilia and secretory cells in the breeding period (Figure 3a). While, the positive staining of TLR4 was only observed in the epithelial a

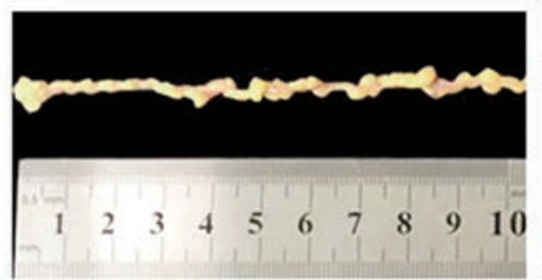

c

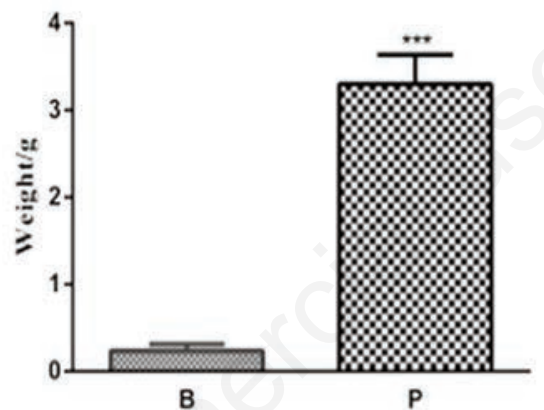
immunostaining of TLR4 was present in pre-hibernation than that of the breeding period (Figure 3b). The expression of MyD88 was also observed in the epidermal and secretory cells of the breeding period and pre-hibernation (Figure 3c, d). During the breeding period, the immunoreactivity cells with cilia (Figure 3b). Stronger b

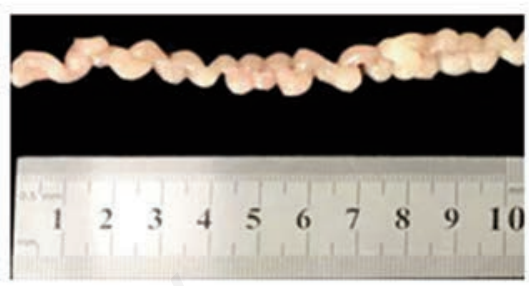

d

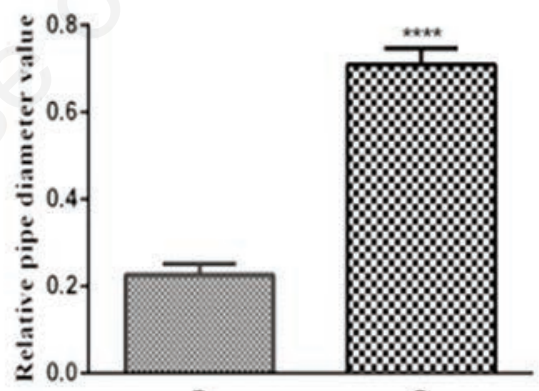

B

p
Figure 1. Changes in oviductal morphological characteristics of Rana dybowskii during the breeding period (a) and pre-hibernation (b). Changes in oviductal weight (c) and relative circumference (d) of Rana dybowskii during the breeding period and pre-hibernation. Bars represent means \pm SD for three independent experiments. Mean values within the columns marked with asterisk were used to indicate significant difference $(P<0.05)$.

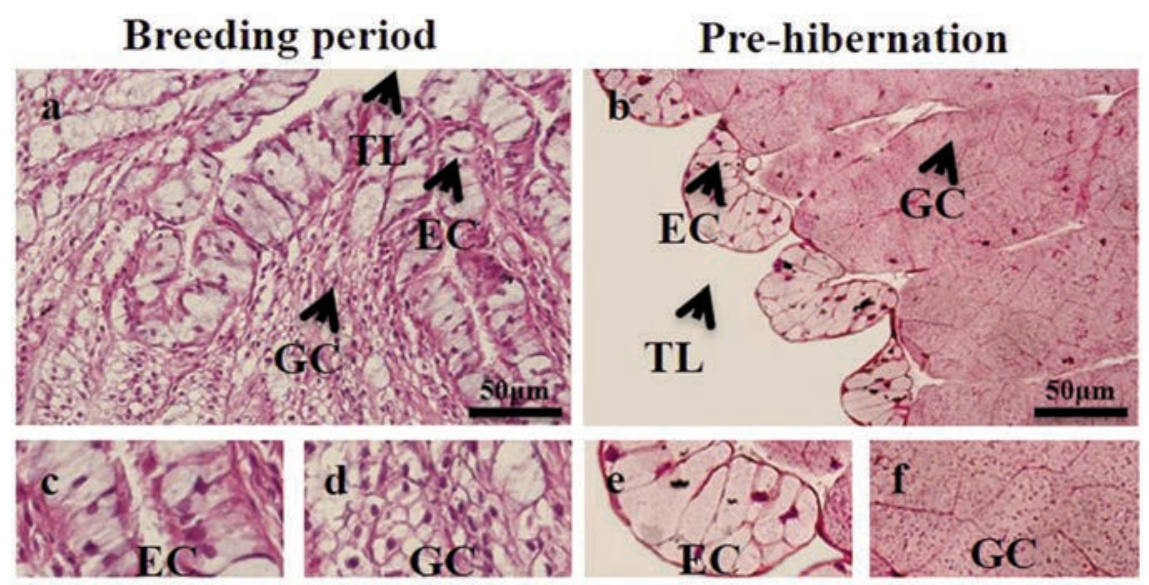

Figure 2. Histological structures of the oviducts in the breeding period (a) and pre-hibernation (b). The local enlarged images represent the sections during the breeding period (c,d) and the pre-hibernation (e,f). B, the breeding period; P, pre-hibernation; EC, epithelial cell; GC, glandular cell; TL, tubule lumen. Scale bars: $50 \mu \mathrm{m}$. 
of MyD88 was more intense in the secretory cells than in epithelial cells with cilia, whereas the staining of MyD88 in epidermal was stronger than secretory cells in the pre-hibernation. The positive signal of IRAK4 was observed in the epithelial and secretory cells during the breeding period (Figure 3e), whereas only in the epithelial cells with cilia during pre-hibernation (Figure 3f). During the breeding period and pre-hibernation, NF- $\kappa \mathrm{B}$ was both expressed in epithelial cells with cilia and secretory cells, the staining in secretory cells and epithelial cells with cilia during pre-hibernation was higher than that in breeding period (Figure 3 g,h).

\section{Protein expression levels of TLR4, MyD88, IRAK4 and NF- $\mathrm{B}$ in Rana dybowskii oviducts}

The results of Western blot analysis of TLR4, MyD88, IRAK4 and NF- $\kappa B$ in the oviduct of Rana dybowskii during the breeding period and pre-hibernation were shown in Figure 4. Western blotting analysis detected bands of TLR4 (Figure 4a), MyD88 (Figure 4b), IRAK4 (Figure 4c) and NF- $\mathrm{BB}$ (Figure 4d) proteins at approximately $90 \mathrm{kD}$, $34 \mathrm{kD}, 54 \mathrm{kD}$ and $61 \mathrm{kD}$, respectively. Each of the antibodies recognized a single band in the oviduct tissues of this species. The results showed that there was no significant difference in protein expression levels of TLR4, IRAK4 and NF- $\kappa$ B p65 subunit between the two periods. However, the protein level of Myd88 was significantly higher in pre-hibernation comparing with the breeding period (Figure 4 a-d).

\section{Relative mRNA expression levels of TLR4, MyD88, IRAK4 and NF-кB in Rana dybowskii oviducts}

The mRNA levels of TLR4, MyD88, IRAK4 and NF- $\mathrm{kB}$ were detected in the oviductal tissues of Rana dybowskii during the breeding period and pre-hibernation
(Figure 5). The results showed that the relative mRNA levels of MyD88 and NF- $\mathrm{B}$ were significantly higher in pre-hibernation compared with the breeding period (Figure 5 b,d), while the mRNA levels of TLR4, IRAK4 had no significant difference between the two periods (Figure $5 \mathrm{a}, \mathrm{c}$ ).

\section{Discussion}

The present study revealed the immunolocalization and expression patterns of TLR4, MyD88, IRAK4 and NF- $\kappa$ B in the oviducts of Rana dybowskii during the

Table 2. Immunohistochemical localization of TLR4, MyD88, IRAK4, NF- $\kappa B$ in the oviduct of Rana dybowskii during the breeding period and pre-hibernation.

\begin{tabular}{lccccccccc} 
& & THRA & & \multicolumn{2}{c}{ MyD88 } & & IRAK4 & \multicolumn{3}{c}{ NF-KB } \\
& B & P & B & P & B & P & B & P \\
Epithelial cell & ++ & ++ & + & ++ & + & ++ & + & ++ \\
Glandular cell & + & - & ++ & + & ++ & - & + & +++ \\
\hline
\end{tabular}

B, breeding period; P, pre-hibernation; -, negative staining; +, positive staining; ++ , strong positive staining; +++ , very strong positive staining and/or no such cell type.
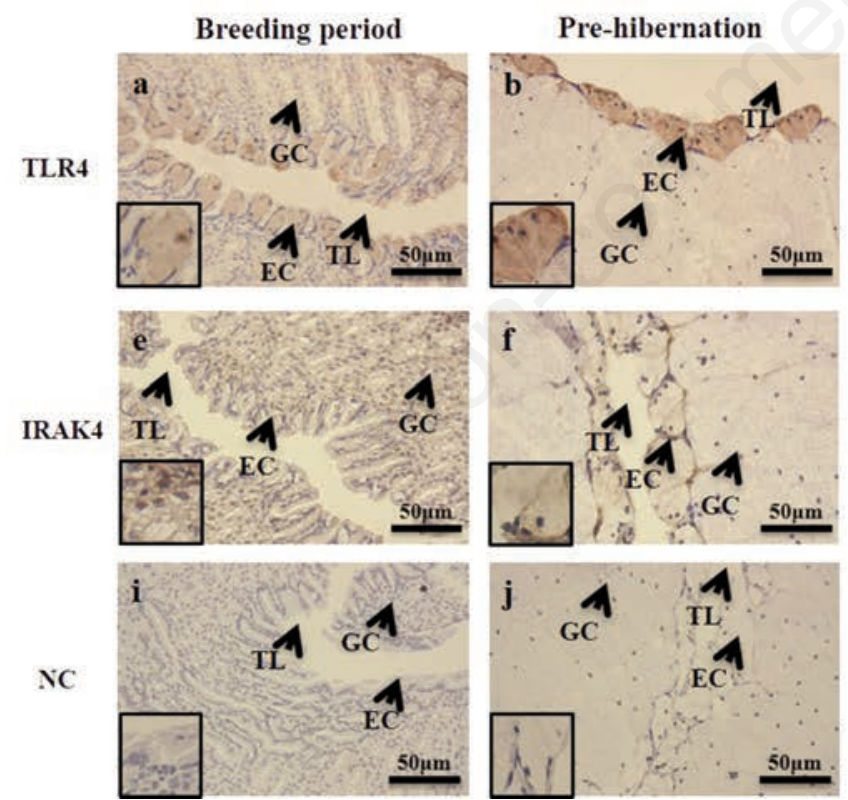
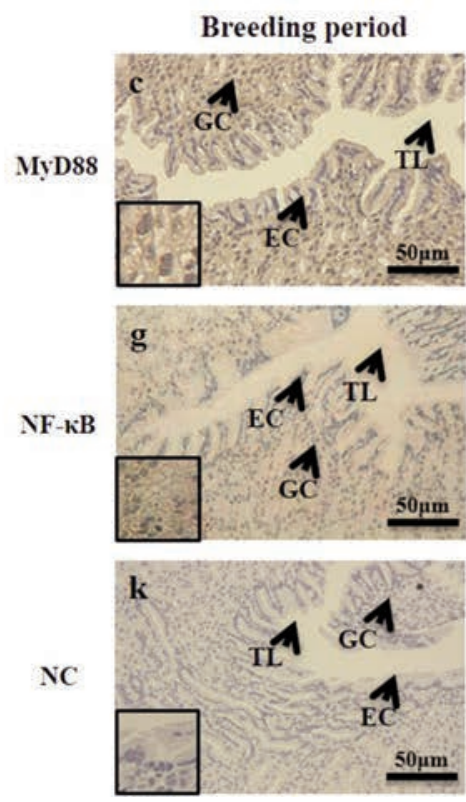
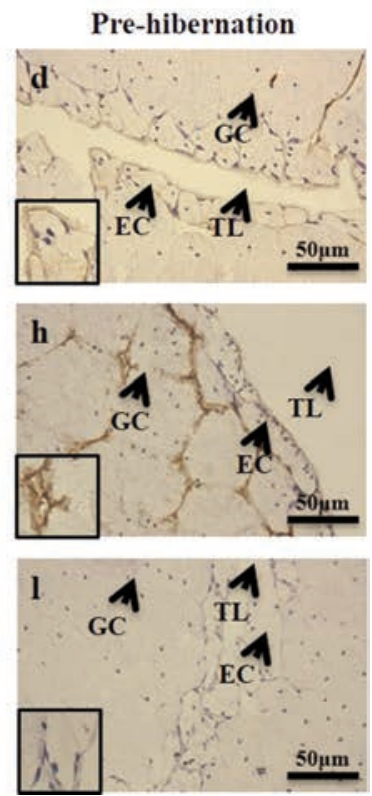

Figure 3. Immunohistochemical localization of TLR4, MyD88, IRAK4 and NF-KB in the oviductal tissues of Rana dybowskii during the breeding period and pre-hibernation. Positive staining of TLR4 was localized in both epithelial of the breeding period and prehibernation (a, b) and stronger positive staining was present in the pre-hibernation period (b). Positive staining of MyD88 was localized in both epithelial and secretory cells of the breeding period and pre-hibernation (c,d) and stronger positive staining was present in the secretory cells of the breeding period (c). Positive staining of IRAK4 was localized in both epithelial and secretory cells of the breeding period and pre-hibernation $(e, f)$ and stronger positive staining was present in the epithelial cells with cilia of the pre-hibernation period (f). Positive staining of NF-KB was localized in both epithelial and secretory cells of the breeding period and pre-hibernation (g,h) and stronger positive staining was present in the secretory cells of the pre-hibernation period (h). No immunostaining was detected in the negative control sections (i,j,k,l). EC, epithelial cell; GC, glandular cell; TL, tubule lumen; NC, negative control. Scale bars: $50 \mu \mathrm{m}$. 
breeding period and pre-hibernation. The results showed that TLR4, MyD88, IRAK4 and NF- $\kappa B$ were expressed in the epithelial cells with cilia and secretory cells of the oviducts of Rana dybowskii during the breeding period and pre-hibernation. Western blotting results showed that these proteins had no significant difference between the two periods except MyD88 whose protein level was significantly higher in pre-hibernation. Moreover, the expression levels of TLR4, MyD88, IRAK4 and NF- $\kappa \mathrm{B}$ mRNA were significantly higher in pre-hibernation than those of the breeding period. These findings suggested that TLR4/MyD88 signaling might play an immune role in regulating the oviductal functions of Rana dybowskii during the breeding period and pre-hibernation.

Mucosal epithelial cells with cilia of the female genital organs such as oviduct could regulate bacterial infection and the mechanism was mainly depended on the expression of TLRs which were key members of PRRs. ${ }^{20,21}$ TLR4 was unique among TLRs because it had the ability to express main inflammatory molecules via both MyD88dependent and MyD88-independent pathways. ${ }^{22}$ The present results showed that TLR4/MyD88 signaling proteins were predominantly localized in the epithelial cells with cilia and glandular cells of the oviducts during the breeding period and pre-hibernation. Moreover, Western blot results of TLR4/MyD88 signaling proteins in oviductal extract of Rana dybowskii showed a high trend in pre-hibernation. These findings were similar to that found in other animals. In Pelodiscus sinensis turtles, TLR4 was widely distributed in the oviduct, particularly in the epithelial cell membrane, which indicated that it played an important role in the protection of the resident sperm in the oviduct against microorganisms. ${ }^{23}$ In TLR4/MyD88 signaling knockout mice, many immune responses were compromised and the prolonged infection leading to chronic oviduct diseases, which indicated

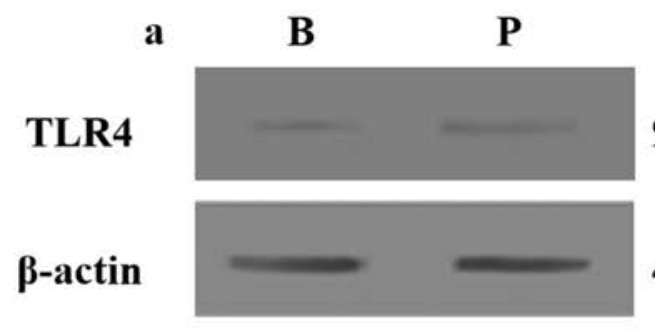

90KDa

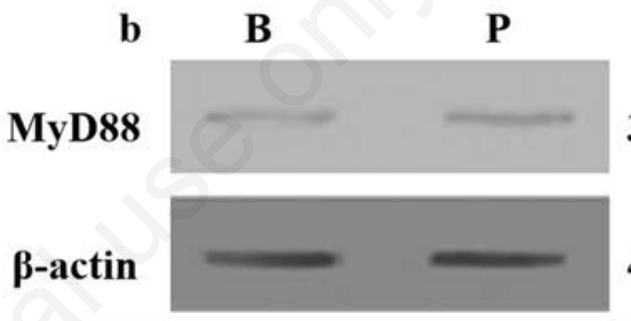

34KDa

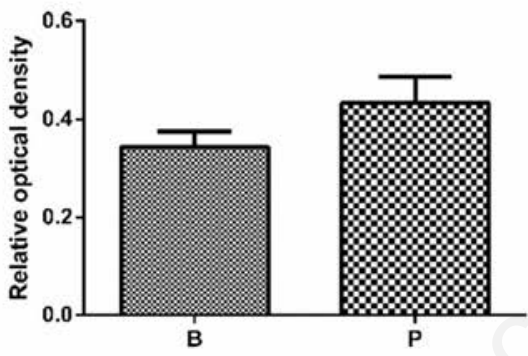

43KDa

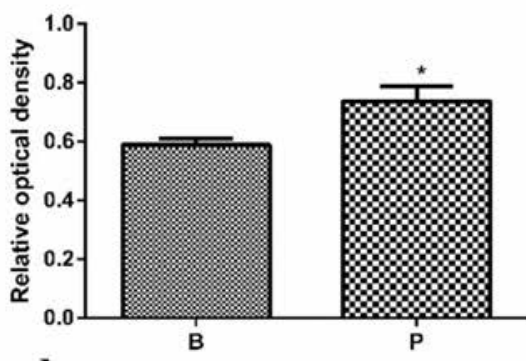

c

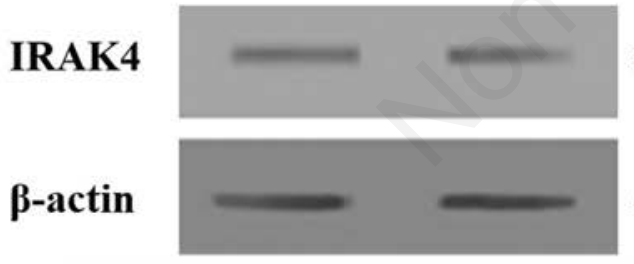

51KDa

d

43KDa

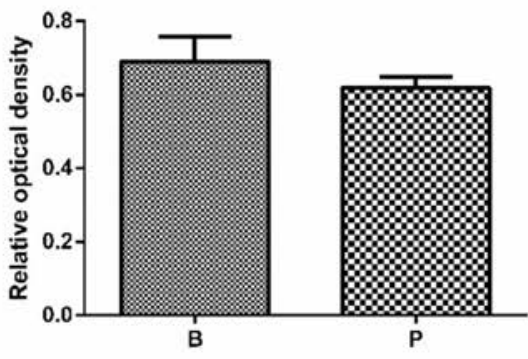

43KDa

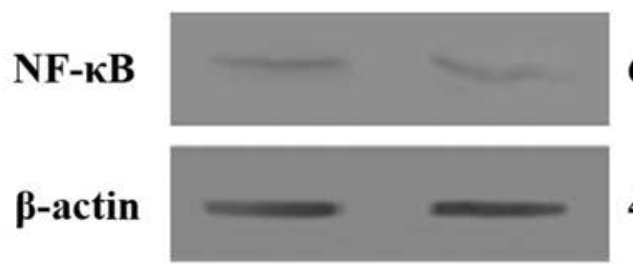

61KDa

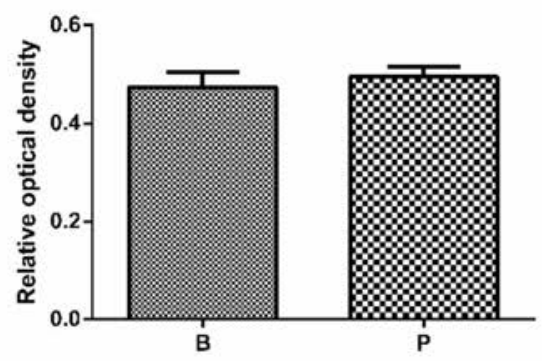

Figure 4. Western blotting of TLR4, MyD88, IRAK4 and NF-KB in the oviductal tissues of Rana dybowskii during the breeding period (B) and pre-hibernation (P). Positive bands of TLR4, MyD88, IRAK4 and NF-KB were observed in the position of about 90kD (a), $34 \mathrm{kD}$ (b), $54 \mathrm{kD}$ (c) and $61 \mathrm{kD}$ (d), respectively. $\beta$-actin was used as controls to correct for loading in each lane. The expression levels were determined by densitometric analysis. Bars represent means \pm SD for three independent experiments. Mean values within the columns marked with asterisk were used to indicate significant difference $(P<0.05)$. 
that TLR4/MyD88 signaling had significant role in immune responses. ${ }^{24}$ Therefore, the present results supported the views that TLR4 played a role in the immune defense function of Rana dybowskii oviducts by identifying MyD88 to activate the downstream signaling pathway, such as transcription factor NF- $\mathrm{KB}$, causing the immune response. ${ }^{25}$

In the MyD88-dependent pathway, the recruitment and formation of MyD88IRAK4- IRAK1 complex (also called Myddosome) leaded to IRAK1 phosphorylation and its dissociation from the complex, free IRAK1 activated cascades of downstream kinases and contributed to the activation of NF- $\kappa B .26-28$ Previous studies showed that macrophages harboring kinaseinactive IRAK4 exhibited deficient activation of IRAK1, MAPKs and NF- $\kappa \mathrm{B}$, and reduced expression of TNF- $\alpha$, IL-6, IL-1 $\beta$ after bacterial infections, ${ }^{29}$ which suggested that the expression of NF- $\kappa \mathrm{B}$ and downstream pro-inflammatory cytokines were affected by IRAKs. In this study, expression of IRAK4 and NF- $\mathrm{KB}$ were found in the breeding period and pre-hibernation, which suggested TLR4/MyD88 signaling could induce the next reaction by activation of IRAK4. The NF- $\mathrm{B}$ proteins were key regulators of innate and adaptive immune responses that could accelerate cell proliferation, inhibit apoptosis, promote cell migration and invasion, and stimulate angiogenesis and metastasis. ${ }^{30}$ There were two general types of activation of NFKB signaling pathways: the canonical NF- $\kappa$ B pathway and the alternative (also known as noncanonical) $\mathrm{NF}-\kappa \mathrm{B}$ pathway, of which the canonical $\mathrm{NF}-\kappa \mathrm{B}$ pathway is more important. ${ }^{31}$ Typical targets for classical NFKB signaling pathways included genes encoding proinflammatory cytokines (such as TNF, IL1 and IL6), and so on. ${ }^{28}$ Those evidence indicated that NF- $\kappa$ B played a central role in the regulation of inflammatory responses at the cell levels. In addition, NF- $\kappa \mathrm{B}$ was able to regulate the gene expression of some cell proliferation and survival, such as cyclin D1, D2 and cyclooxygenase 2 (COX-2). ${ }^{32}$ This suggested that NF- $\kappa \mathrm{B}$ could not only regulate inflammatory responses, but also induce cell proliferation and survival in immune responses. In this study, $\mathrm{NF}-\kappa \mathrm{B}$ was expressed in the breeding period and pre-hibernation, and its expression levels illustrated a high trend from the breeding period to pre-hibernation, which implied that NF- $\kappa \mathrm{B}$ played an important regulatory role in seasonal changes of oviductal functions.

IL- $1 \beta$ as a cytokine, was a major participant in a wide range of autoinflammatory diseases and played an important role in reproductive processes including non-mammalian vertebrates. ${ }^{33,34}$ Previous studies showed that IL-1 $\beta$ could participate in prostaglandin synthesis, fallopian tube contraction, gamete and embryo transport and successful implantation. ${ }^{35,36}$ TLRs recognized bacterial and viral components in the ovary and oviduct and then activated transcription factors through MyD88 pathway to induce NF- $\kappa \mathrm{B}$ activation. ${ }^{37} \mathrm{NF}-\kappa \mathrm{B}$, a transcription factor, could up-regulate the release of multiple inflammatory cytokines, such as IL-1 $\beta$ which further perpetuated the inflammatory cascades. ${ }^{38}$ The previous

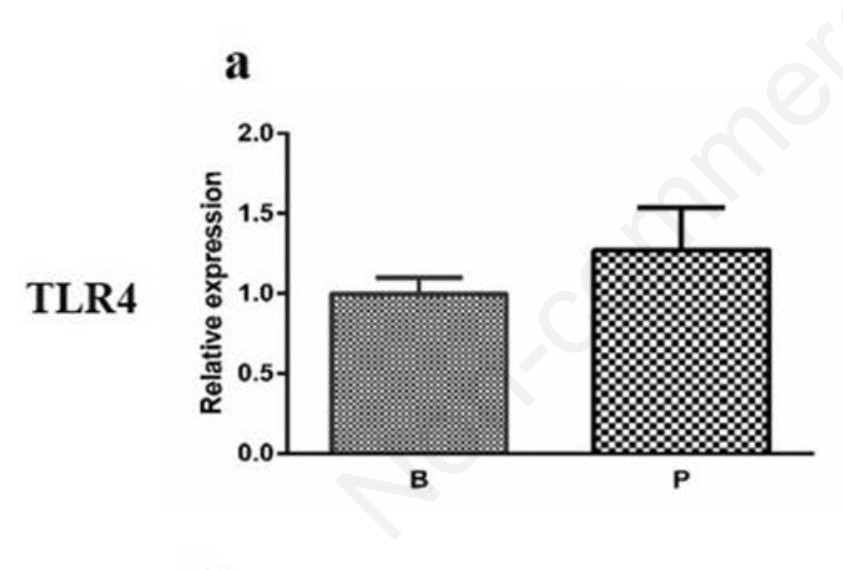

c

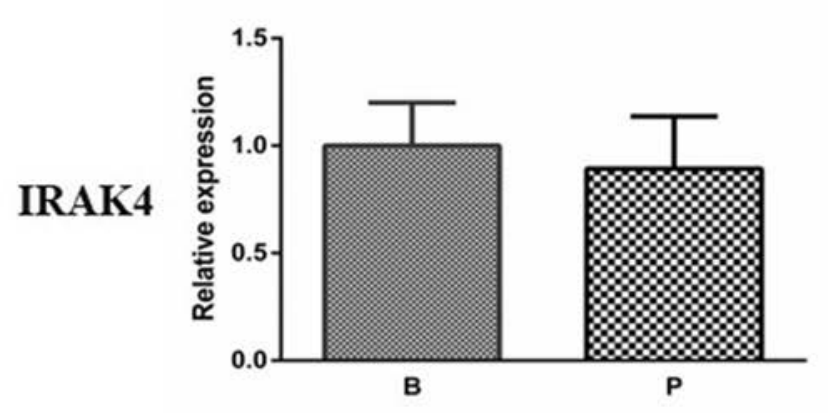

b

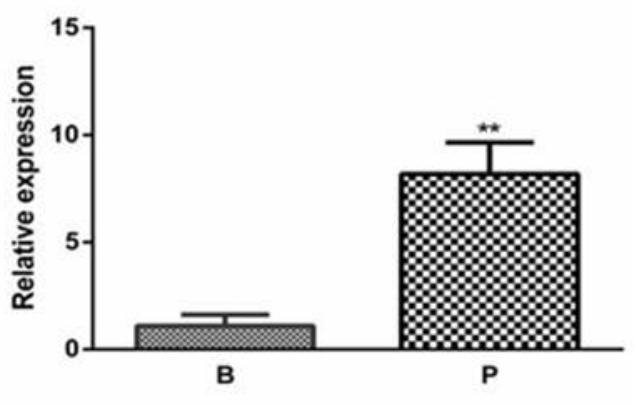

d

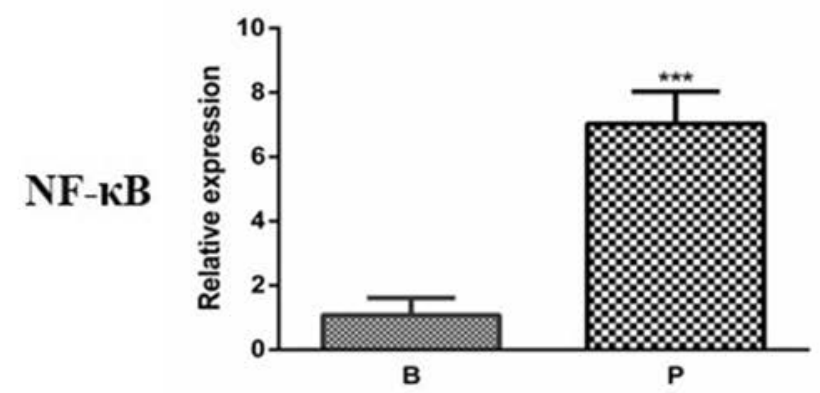

Figure 5. Real-time PCR results of TLR4, MyD88, IRAK4 and NF- $\mathrm{KB}$ in Rana dybowskii oviducts of the breeding period and pre-hibernation. The relative mRNA levels of TLR4, MyD88, IRAK4 and NF- $K B$ in Rana dybowskii in the breeding period and pre-hibernation oviduct were shown in $(a, b, c, d)$, respectively. Bars represent means \pm SD for three independent experiments. Mean values within the columns marked with asterisk were used to indicate significant difference $(P<0.05)$. 
study showed that IL-1 $\beta$ and IL-1R1 were localized in the oviductal tissues of Rana dybowskii during the breeding period and pre-hibernation, but higher expression levels of IL-1 $\beta$ and IL-1R1 were found in prehibernation rather than those of the breeding period. ${ }^{18}$ The present study demonstrated that the expression patterns of TLR4/MyD88 signaling were correlated with changes in immunoreactivities of IL$1 \beta$ and IL-1R in the oviductal tissues of Rana dybowskii. These findings proposed TLR4/MyD88 signaling as a possible upstream mediator regulating the oviductal functions of Rana dybowskii during prehibernation and the breeding period.

In summary, our previous studies showed that IL-1 $\beta$ and IL-1R were found in the oviducts of Rana dybowskii, and IL- $1 \beta$ might be involved in immune and inflammatory responses. ${ }^{18}$ The present study demonstrated that TLR4, MyD88, IRAK4 and NF- $\kappa \mathrm{B}$ were expressed in the oviducts of Rana dybowskii during the breeding period and pre-hibernation. These results suggested that TLR4 might regulate the secretion of cytokines via the MyD88 signaling pathway, which plays a regulatory role in the immune response of Rana dybowskii oviducts. The data presented here will greatly aid the dissection of TLR4 signaling pathway in the oviduct of amphibians.

\section{References}

1. Weng J, Liu Y, Xu Y, Hu R, Zhang H, Shen X, et al. Expression of P450arom and estrogen receptor alpha in the oviduct of Chinese brown frog (Rana dybowskii) during prehibernation. Int $\mathrm{J}$ Endocrinol 2015;2015:283085.

2. Chen S, Palma-Vera S, Kempisty B, Rucinski M, Vernunft A, Schoen J, et al. In vitro mimicking of estrous cycle stages: dissecting the Impact of estradiol and progesterone on oviduct epithelium. Endocrinology 2018;159:3421-32.

3. Yu H, Hackenbroch L, Meyer F, Reiser J, Razzazi-Fazeli E, Nöbauer K, et al. Identification of rabbit oviductal fluid proteins involved in pre-fertilization processes by quantitative proteomics. Proteomics 2019;19:e1800319.

4. Su H, Zhang H, Wei X, Pan D, Jing L, Zhao D, et al. Comparative proteomic analysis of rana chensinensis oviduct. Molecules 2018;23:1384.

5. Liu Y, Weng J, Huang S, Shen Y, Sheng $X$, Han Y, et al. Immunoreactivities of PPAR 2 2, leptin and leptin receptor in oviduct of Chinese brown frog during breeding period and pre-hibernation. Eur J Histochem 2014;58:2422.

6. Marey M, Yousef M, Kowsar R,
Hambruch N, Shimizu T, Pfarrer C, et al. Local immune system in oviduct physiology and pathophysiology: attack or tolerance? Domest Anim Endocrinol 2016;56:S204-11.

7. Menchetti L, Barbato O, Filipescu I, Traina G, Leonardi L, Polisca A, et al. Effects of local lipopolysaccharide administration on the expression of Toll-like receptor 4 and pro-inflammatory cytokines in uterus and oviduct of rabbit does. Theriogenology 2018; 107:162-74.

8. Gao Q, Yin F, Zhang C, Yue Y, Sun P, Min $\mathrm{M}$, et al. Cloning, characterization, and function of MyD88 in silvery pomfret (Pampus argenteus) in response to bacterial challenge. Int J Biol Macromol 2017; 103:327.

9. Kowsar R, Kowsar Z, Miyamoto A. Upregulated mRNA expression of some anti-inflammatory mediators in bovine oviduct epithelial cells by urea in vitro: Cellular pathways by Reactome analysis. Reprod Biol 2019;19:75-82.

10. Hu Q, Mao D. Histone deacetylase inhibitor SAHA attenuates post-seizure hippocampal microglia TLR4/MYD88 signaling and inhibits TLR4 gene expression via histone acetylation. BMC Neurosci 2016;17:22.

11. Thorburn A, Tseng H, Donovan C, Hansbro N, Jarnicki A, Foster P, et al. TLR2, TLR4 and MyD88 mediate allergic airway disease (AAD) and streptococcus pneumoniae-Induced suppression of AAD. PLoS One 2016;11: e0156402.

12. Vilahur G, Badimon L. Ischemia/reperfusion activates myocardial innate immune response: the key role of the toll-like receptor. Front Physiol 2014;5:496.

13. Jing X, Tian Z, Gao P, Xiao H, Qi X, Yu $Y$, et al. HBsAg/ $\beta 2$ GPI activates the $\mathrm{NF}-\kappa \mathrm{B}$ pathway via the TLR4/MyD88/I $\kappa \mathrm{B} \alpha$ axis in hepatocellular carcinoma. Oncol Rep 2018; 40:1035-45

14. Zhang P, Xin X, Fang L, Jiang H, Xu X, $\mathrm{Su} \mathrm{X}$, et al. HMGB1 mediates, Aspergillus fumigatus-induced inflammatory response in alveolar macrophages of COPD mice via activating $\mathrm{MyD} 88 / \mathrm{NF}-\mathrm{kB}$ and $\mathrm{syk} / \mathrm{PI} 3 \mathrm{~K}$ signalings. Int Immunopharmacol 2017;53:125-32.

15. Kim S, Jin Y, Choi Y, Park T. Resveratrol exerts anti-obesity effects via mechanisms involving down-regulation of adipogenic and inflammatory processes in mice. Biochem Pharmacol 2011;81:1343-51.

16. Xiao X, Miao H, Xu Y, Zhang J, Chai L, $\mathrm{Xu}$ J, et al. Analysis of skin and secre- tions of Dybowski's frogs (Rana dybowskii) exposed to Staphylococcus aureus or Escherichia coli identifies immune response proteins. Vet $\mathrm{J}$ 2014;200:127-32.

17. Shen Y, Liu Y, Ma J, Ma X, Tian Y, Zhang $\mathrm{H}$, et al. Immunoreactivity of ckit receptor protein during the prehibernation period in the oviduct of the Chinese brown frog, Rana chensinensis. J Vet Med Sci 2012;74:209-13.

18. Hu R, Liu Y, Deng Y, Ma S, Sheng X, Weng $Q$, et al. Immunoreactivities of IL-1 $\beta$ and IL-1R in oviduct of Chinese brown frog (Rana dybowskii) during pre-hibernation and the breeding period. Acta Histochem 2016;118:164-9.

19. Xi L, Wang C, Chen P, Yang Q, Hu R, Zhang $\mathrm{H}$, et al. Expressions of IL-6, TNF- $\alpha$ and NF- $\kappa$ B in the skin of Chinese brown frog (Rana dybowskii). Eur J Histochem 2017;61:2834.

20. D'Ippolito S, Di Nicuolo F, Pontecorvi A, Gratta M, Scambia G, Di Simone N, et al. Endometrial microbes and microbiome: Recent insights on the inflammatory and immune "players" of the human endometrium. Am J Reprod Immunol 2018;80:e13065.

21. Sheldon I, Owens S, Turner M. Innate immunity and the sensing of infection, damage and danger in the female genital tract. J Reprod Immunol 2017;119:67-73.

22. Rocha D, Caldas A, Oliveira L, Bressan J, Hermsdorff $H$. Saturated fatty acids trigger TLR4-mediated inflammatory response. Atherosclerosis 2016; 244:211-55.

23. Li Q, Hu L, Yang P, Zhang Q, Waqas Y, Liu $T$, et al. Expression of TLR2/4 in the sperm-storing oviduct of the Chinese soft-shelled turtle Pelodiscus sinensis during hibernation season. Ecol Evol 2015;5:4466-79.

24. Nagarajan U, Sikes J, Prantner D, Andrews C, Frazer L, Goodwin A, et al. MyD88 deficiency leads to decreased NK cell gamma interferon production and $\mathrm{T}$ cell recruitment during Chlamydia muridarum genital tract infection, but a predominant Th1 response and enhanced monocytic inflammation are associated with infection resolution. Infect Immun 2011;79: 486-98

25. Feng H, Su R, Song Y, Wang C, Lin L, $\mathrm{Ma}$ J, et al. Positive correlation between enhanced expression of TLR4/MyD88/NF-kB with insulin resistance in placentae of gestational diabetes mellitus. PLoS One 2016; 11:e0157185.

26. Ahmad R, Shihab P, Thomas R, Alghanim M, Hasan A, Sindhu S, et al. 
Increased expression of the interleukin1 receptor-associated kinase (IRAK)-1 is associated with adipose tissue inflammatory state in obesity. Diabetol Metab Syndr 2015;7:71.

27. Wang Y, Mao J, Zhou M, Jin Y, Lou C, Dong $\mathrm{Y}$, et al. Polysaccharide from Phellinus Igniarius activates TLR4mediated signaling pathways in macrophages and shows immune adjuvant activity in mice. Int $\mathrm{J}$ Biol Macromol 2019;123:157-66.

28. Lyu C, Zhang Y, Gu M, Huang Y, Liu G, Wang C, et al. IRAK-M Deficiency exacerbates ischemic neurovascular injuries in experimental stroke mice. Front Cell Neurosci 2018;12:504.

29. Pattabiraman G, Murphy M, Agliano F, Karlinsey K, Medvedev A. IRAK4 activity controls immune responses to intracellular bacteria Listeria monocy- togenes and Mycobacterium smegmatis. J Leukoc Biol 2018;104:811-20.

30. Taniguchi K, Karin M. NF- $\kappa B$, inflammation, immunity and cancer: coming of age. Nat Rev Immunol 2018;18:309-24.

31. Markopoulos G, Roupakia E, Tokamani M, Alabasi G, Sandaltzopoulos R, Marcu K, et al. Roles of NF- $\kappa$ B signaling in the regulation of miRNAs impacting on inflammation in cancer. Biomedicines 2018;6.pii: E40.

32. Li X, Jiang S, Tapping R. Toll-like receptor signaling in cell proliferation and survival. Cytokine 2010;49:1-9.

33. Peiró C, Lorenzo Ó, Carraro R, Sánchez-Ferrer C. IL-1 $\beta$ Inhibition in cardiovascular complications associated to diabetes mellitus. Front Pharmacol 2017;8:363.

34. Dinarello C. Overview of the interleukin-1 family of ligands and recep- tors. Semin Immunol 2013;25:389-93.

35. Robertson S, Chin P, Femia J, Brown H. Embryotoxic cytokines - Potential roles in embryo loss and fetal programming. J Reprod Immunol 2018;125:80-8.

36. Wijayagunawardane M, Miyamoto A. Tumor necrosis factor $\alpha$ system in the bovine oviduct: A possible mechanism for embryo transport. J Reprod Dev 2004;50:57-62.

37. Yoshimura, Y. Avian $\beta$-defensins expression for the innate immune system in hen reproductive organs. Poultry Science 2015;94:804-9.

38. Chunhua M, Hongyan L. Protective effect of pilose antler peptide on carbon tetrachloride-induced hepatotoxicity in mice. Int J Biol Macromol 2017;99: 648-54. 